\title{
Frequency Extraction of Current Signal Spectral Components: A New Tool for the Detection of Rotor Electrical Faults in Induction Motors
}

\author{
P. A. Panagiotou, I. Arvanitakis, N. Lophitis, Member, IEEE and K. N. Gyftakis, Member, IEEE
}

\begin{abstract}
This work expands the classical current signature analysis in induction machines in a two-stage spectral decomposition manner. The proposed methodology can be summarized in two main steps: initially, the current signals are analyzed using a time frequency representation, with the analysis focusing on the steady-state regime; thereafter, frequency extraction is applied to the spectral signatures of interest, aiming to identify specific fault related harmonic subcomponents induced by the fault related speed ripple effect. The proposed approach is verified experimentally on a $4 \mathrm{~kW}$ induction motor.
\end{abstract}

Index Terms - broken bars, frequency extraction, spectral components, t-f analysis

\section{INTRODUCTION}

$\mathrm{T}$ THE field of induction machines' condition monitoring has been rapidly advancing in the past few decades and adjusting to the complexity of the modern industrial demands, in order to assert safety, prevent downtimes or emergency maintenance and -of course- to obviate any potential financial casualties. Rotor faults are important to detect at early stages, since their appearance can progress internally affecting the rest of the cage and the rotor iron core.

For the detection and diagnosis of rotor faults, the early research in the field handled the monitoring of the line currents by examination of the signal anomalies over time or by examination of its frequency spectra [1]-[4]. The reason was the fact that the acquisition of a current measurement holds some advantages like: its reliability and low cost [4][5]; it can be done safely from a distance, since it is usually measured for control and stabilization purposes [5]; its nonintrusive character and low computational complexity [5]-[7] and -most importantly- it can be applied on-line [3]-[7]. This was the stepping-stone for the commercially established monitoring equipment applying Motor Current Signature Analysis (MCSA) and also for the archiving of the first actual

P. A. Panagiotou and N. Lophitis are with the School of CEM and Research Institute for Future Transport \& Cities, Coventry University, UK (e-mail: pansko.qd@gmail.com,n.lophitis@coventry.ac.uk).

Ioannis Arvanitakis is with School of CEM, Coventry University (email: ac7632@coventry.ac.uk).

Konstantinos N. Gyftakis is with the School of Engineering, University of Edinburgh, UK (e-mail: k.n.gyftakis@ieee.org). on-field industrial history case-studies by means of currents [4]-[7].

Subsequently, the theoretical background and analytical modelling approaches on the harmonic content started to update [8]. However, in the light of reports mentioning some MCSA deficiencies [4], the knowledge on specific fault related harmonic components and their mechanisms required further investigations and updating [9]-[11]. In sequence, questions were raised for the adequacy of classical signal processing techniques like the Fast Fourier Transform (FFT) [12]-[14]. This triggered the application of other types of analyses along with the reformation of stationarity/nonstationarity assumptions during fault conditions [15]-[17]. Developments to that direction include: the Hilbert Transform [14], [18]-[19], envelope analysis [20], the Wavelet Transform [21]-[23] and other time-frequency representations by means of transforms (Gabor [24], STFT [25]-[27], Adaptive Slope [28] etc.) or distributions (WignerVille [29]-[30] etc.). Meanwhile, further options of measurements were also examined with success, like torque monitoring [31]-[32], stray flux signature analysis (SFSA) [33]-[35] and the zero-sequence current (ZSC) [36]. Some works like [3], [33] and [37]-[38] suggest the use of additional monitoring methods to be used complementary with MCSA for adequate and reliable diagnosis.

During the last decade, a series of more advanced approaches have been proposed for broken rotor bar detection. These include statistical-based approaches [39][40], classification techniques [41]-[42] and methods using machine learning tools [43], while the field continues to update with reported MCSA industrial case-studies [22], [44].

In this work, a newly introduced approach is presented for the detection of rotor faults. Given the existing knowledge on frequency tracking with MCSA and the fault related signatures during broken rotor bars existence, a t-f representation is used on the phase current signals to visualize the signatures of interest. Accounting for the speed ripple effect, the spectral density information at steady state is individualized and extracted through the spectrogram for each harmonic of interest. The extracted spectral trajectories are then examined as periodical oscillations over time and 
their FFT is evaluated for the frequency tracking of faultrelated subcomponents. The diagnostic validity of the method is assessed via extensive 2D FEA simulations on a $4 \mathrm{~kW}$ induction motor and experimental testing.

\section{THEORETICAL BACKGROUND}

\section{A. Broken Bar Diagnostics: Classical MCSA \& TCSA}

At the event of a bar breakage, the bar is electrically disconnected from the rest of the cage. Due to the asymmetry caused by this open-circuit condition at the point of breakage, two counter-rotating magnetic fields of frequencies $\pm s f_{s}$ exist in the rotor [2]-[10], where $s$ the motor slip and $f_{s}$ the fundamental supply frequency.

The chain reaction of harmonics over the frequency spectra due to the counter rotating field at $-s \cdot f_{s}$ and the genesis of fault related speed-ripple effect sidebands, is analytically described in [2]-[4], [10] and [23]. The equation for tracking the frequency signatures induced by the broken bar fault is the following [12], [18], [21], [24]:

$$
f_{b b}=\left[\frac{k}{p}(1-s) \pm s\right] f_{s},
$$

where $p$ is the number of pole pairs, $s$ the motor slip and $k \in$ $\mathbb{Z}$ such that $\frac{k}{p} \in \mathbb{Z}$.

Traditionally applied MCSA inspects those signatures over the frequency spectra to evaluate their amplitudes, while the motor is operating at the late steady-state. The sum of the fundamental harmonic's sidebands at $\pm 2 s f_{s}$ is examined in [2], proven as a reliable diagnostic index for fabricated rotors. Broken bars are examined by MCSA means in [3], combined with instantaneous torque and instantaneous power accounting for speed and torque ripples. Combination of this knowledge is then used by the authors in [4], where rotor electric and magnetic asymmetries are deciphered for laboratory-scale motors and for industrial-oriented motors with "spider"-designed rotors. Moreover, [8] validates the theoretical and experimental frequency content for the stator and rotor space harmonics under healthy condition, one, two and three broken bars. A device for online monitoring of rotor faults using the two aforementioned sidebands is presented in [10], while a novel approach for monitoring the sidebands' behaviour is proposed in [14] combining the classical FFT method with phase analysis via the Hilbert Transform. The sidebands amplitude and phase modulations are examined in [15] by MCSA means, while [20] presents a low-cost diagnosis framework for diagnosing rotor asymmetries at low slip values with reduced envelope analysis.

Nevertheless, the existence of a fault and its progression are governed by non-stationarity [17]-[19]. Except from the frequencies' evolution and transitions during the transient start-up, at the presence of a fault the machine is subjected to local transients. Even at the steady-state regime, the disturbances caused by the fault are affecting the acquired signals' instantaneous frequency [13]-[19], or implying varying and oscillating amplitudes [14], [15]-[17], [35], [40]. These drawbacks can be a vice when using MCSA on the pipeline for a diagnostic decision. Therefore, Transient Current Signature Analysis (TCSA) [21]-[23] and similar approaches have been proposed [24]-[30]. These techniques track the evolution of frequencies during the start-up transient -or other transient regimes- in terms of trajectories or orbits [12], [13], [21]-[30]; otherwise, they demodulate and decompose the studied signals' spectral components to examine if any diagnostic information is comprised in the instantaneous frequencies [14]-[19].

\section{B. Time-Frequecny Analysis \& STFT}

The STFT analysis is a commonly used time-frequency representation [25]-[27]. The continuous time STFT $X(t, f)$ of a signal is a function of both time $t$ and frequency $f$ and can be computed from the FFT over a sliding window by the following equation [25], [35]:

$$
X(t, f)=\int_{-\infty}^{+\infty} x(t) w(t-\tau) e^{-j 2 \pi f t} d t
$$

where $x(t)$ the given signal, $w(t)$ the sliding window, $\tau$ the window shifting factor and $f=2 \pi / \omega$ the frequency. Equation (2) provides the joint t- $f$ representation of the spectral density by means of the spectrogram:

$$
S(t, f)=|X(t, f)|^{2}
$$

For the case of a sampled and discretized signal, the discrete-time STFT [49] is given from:

$$
X[t, f]=\sum_{n=t-L / 2}^{t+L / 2}\left[x_{n} \cdot w_{n-t}\right] \cdot e^{-j 2 \pi f n t},
$$

where $t$ the discrete time, $f$ the frequency and $L$ the window length.

\section{Windowing Limits \& Spectral Components Extraction}

The transformation for the STFT analysis is derived using a Kaiser-Bessel windowing function, with parameter $\beta=$ 18.13 and $70.4 \%$ overlap between the frames. The selection accrued from fine tuning of the parameters accounting for two factors: initially, to achieve a windowing with a response of unitary ripple and as close as possible to rectangular; secondly, to yield by the window length a good trade-off between time and frequency resolution in order to observe the harmonic trajectories in the spectrogram [26]-[27], [45]-[46].

Taking advantage of the ripples circled with dashed lines in Fig. 1, the spectral components are extracted for a desired frequency -e.g. the $5^{\text {th }}$ harmonic and its $(5-4 s) f_{s}$ and $(5-$ $6 s) f_{s}$ sidebands- using frequency extraction [35], [46]-[49]. The spectral density information carried in each extracted trajectory is then handled as a function of amplitude and time at this specific frequency. During this frequency extraction process, one should account for the harmonics'separability. This means that the windowing functions will yield a frequency resolution able to localize each trajectory in a 
different time-chunk or frequency-bin to prevent aliasing and spectral leakage diffusion between sidebands [48]. To ensure that, the windowing limits are derived as in [46] and [49], to separate harmonics distanced at least $2 s f_{s}$ from each other.

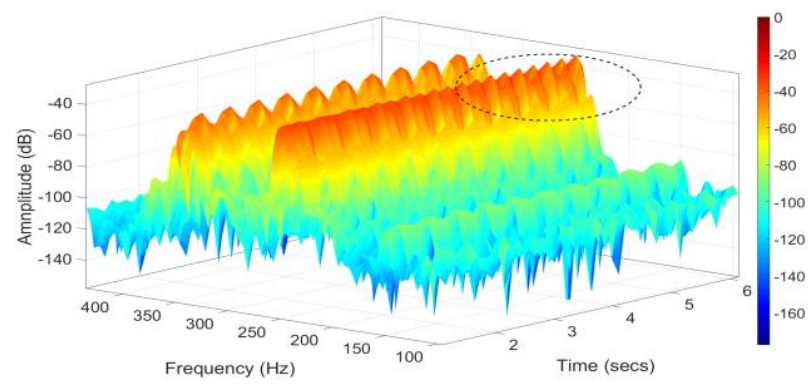

b)

Fig. 1. STFT spectrogram of the phase current for one of the motors examined with FEM (Motor \#1) for the frequency area of the $5^{\text {th }}$ harmonic.

The broken bar fault related components are used to derive from Eq. 3 their spectral content at a fixed constant frequency over time as follows:

$$
S\left(t, f_{a, i}\right)=\left|X\left(t, f_{a, i}\right)\right|^{2},
$$

where each component $f_{a, i}$ regards the $a$-th harmonic of interest and $i=1,2$.

\section{TECHNICAL WORK \& DATA COLLECTION}

\section{A. FEM Models}

One induction machine has been designed and simulated with MagNet 2D FEM software from Mentor/Infologic under healthy operation and with 1 broken rotor bar. The motors' geometrical model is presented in Fig. 2 along with the spatial distribution of the magnetic flux density during faulty condition. The motor's characteristics are described in Table I.

All simulations are run using the Transient FEA solver under 2D with Motion analysis (rotary load-driven), which is a type of simulation accounting for the machines' motion equation, moment of inertia and speed ripple effect. The motors are tested at full load condition, which is the constant rated torque load in each case.

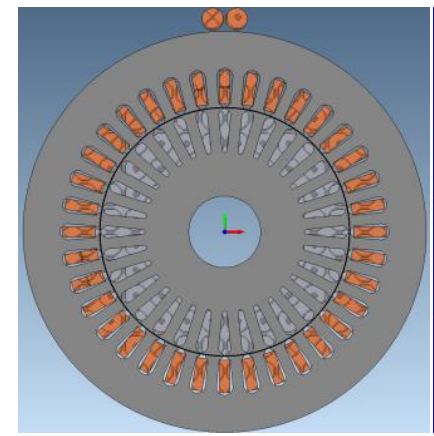

a)

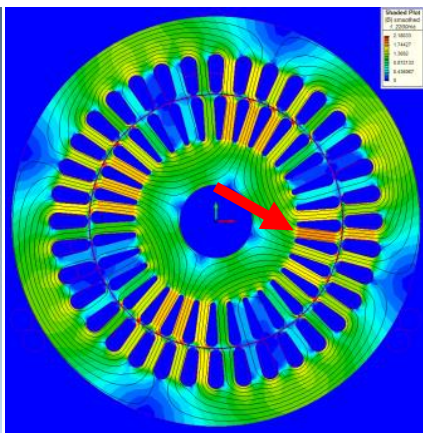

b)
Fig. 2. a) Geometrical solid model of the induction motor and b) spatial distribution of the magnetic flux density $\mathbf{B}(T)$ under broken rotor bar fault.
TABLE I

CHARACTERISTICS OF THE SiMUlated MOTORS

\begin{tabular}{|l|c|}
\hline Frequency & $50 \mathrm{~Hz}$ \\
\hline Stator Connection & $\Delta$ \\
\hline Rated Power & $4 \mathrm{~kW}$ \\
\hline Rated Voltage & $400 \mathrm{~V}$ \\
\hline Rated Current & $10 \mathrm{~A}$ \\
\hline Number of poles & 4 \\
\hline Rated Torque & $26 \mathrm{Nm}$ \\
\hline Stator slots & 36 \\
\hline Rotor slots & 28 \\
\hline
\end{tabular}

\section{B. Experimental Set-up}

The experimental set-up is shown in Fig. 3. Two identical $50 \mathrm{~Hz}, 400 \mathrm{~V}, 4 \mathrm{~kW}$ and 4-pole induction motors have been used during the experimental validation: the healthy and one with the rotor drilled in order to electrically disconnect the bar from the cage. The motors are mechanically coupled to a permanent magnet generator feeding a Y-connected, symmetrical, 3-phase variable resistance. The induction motor's stator winding is connected in $\Delta$.

For the current measurements, three identical current sensors were used. The measurements were logged onto a high resolution, deep memory, 8-channel oscilloscope. Each signal waveform was captured in a frame of $20 \mathrm{sec}$, providing reliable signal representation in time and frequency domain with a sampling frequency of $10 \mathrm{kHz}$.

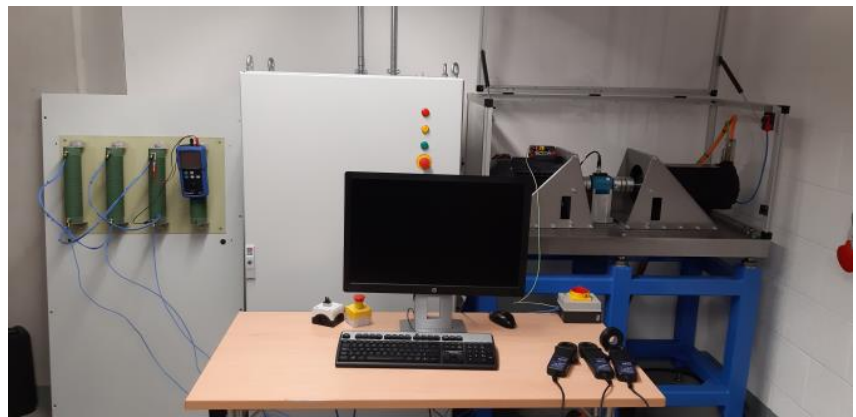

Fig. 3. Experimental set-up

\section{RESULTS \& DISCUSSION}

\section{A. FEM Results}

The extracted spectral information over time regarding the trajectory of the $5^{\text {th }}$ harmonic's lower sideband at $(5-4 s) f_{s}$ is depicted in Fig. 4. From a first inspection it is evident that the healthy model's trajectory (blue) is oscillating at a constant small ripple, while the ripple of the faulty case is increased and indicative for the existence of a rotor fault. The trajectories' FFT spectra are presented in Fig. 5 for the $5^{\text {th }}$ harmonic and in Fig. 6 for the $7^{\text {th }}$ harmonic. 


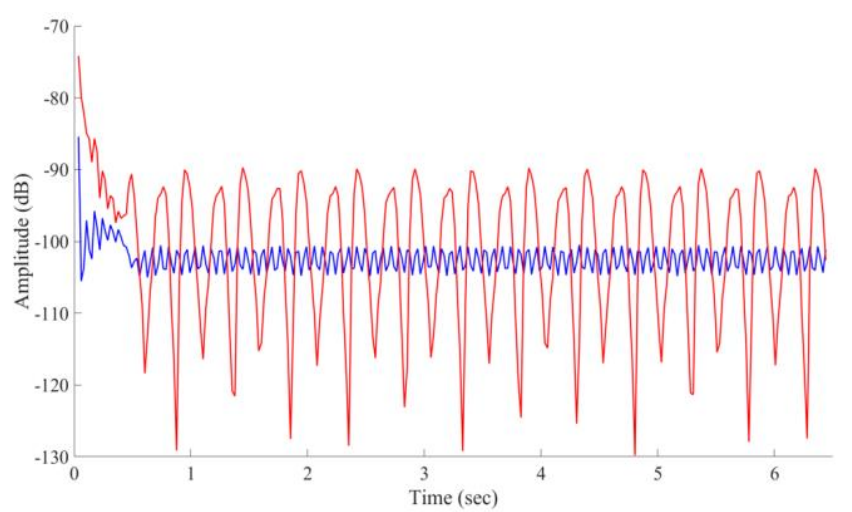

Fig. 4. The extracted $S\left(t, f_{o, 1}\right)$ amplitude information for healthy (blue) and faulty (red) motors of the $(5-4 s) f_{s}$ sideband extracted trajectory.

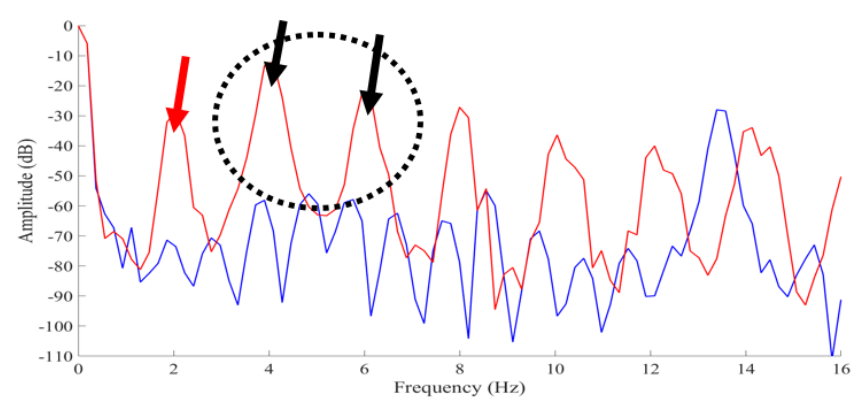

a)

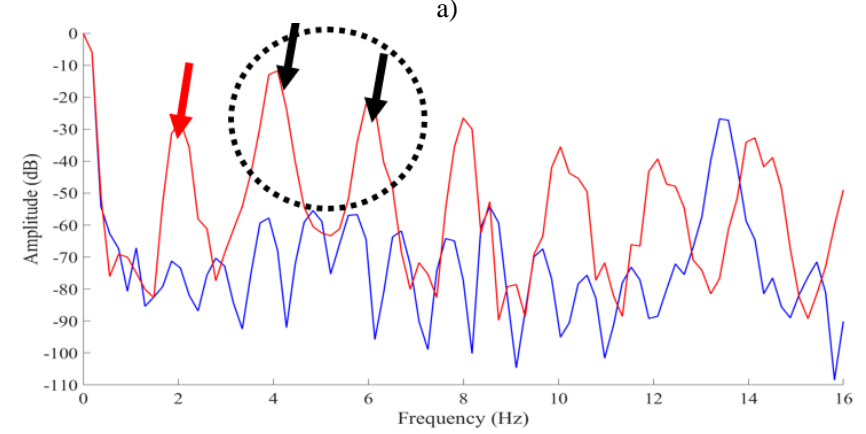

b)

Fig. 5. FFT spectra of the extracted $S\left(t, f_{o, 1}\right)$ information for healthy (blue) and faulty (red) motor at: a) $(5-4 s) f_{s}$ and b) $(5-6 s) f_{s}$.

The amplitudes of the fault related pulsating components regarding both motors are shown in Table II and Table III for the $5^{\text {th }}$ and the $7^{\text {th }}$ harmonic respectively. The components of the faulty motor at frequencies $4 s f_{s}$ and $6 s f_{s}$ (black arrows) rise at the amplitudes of $-12.01 \mathrm{~dB}$ and $-23.63 \mathrm{~dB}$ respectively regarding the $4 s f_{s}$ sideband. In the trajectory of the $6 s f_{s}$ sideband, the amplitudes are $-11.75 d B$ and $-23.24 d B$ respectively (Table II). These components are practically inexistent in the healthy motor $(\leq-50 \mathrm{~dB})$. Interestingly, the component at $2 s f_{s}$ is inexistent in the healthy motor while present in the faulty motor. That is due to the speed ripple effect.

TABLE II

FFT AMPLITUDES OF THE $5^{\text {TH }}$ HARMONIC'S EXTRACTED COMPONENTS

\begin{tabular}{ccccc}
\hline \hline \multirow{2}{*}{ Motor } & \multicolumn{2}{c}{$5{f f s-4 s f_{s}}$} & \multicolumn{2}{c}{$5 f f_{s}-6 s f_{s}$} \\
\cline { 2 - 5 } & $4 s f_{s}$ & $6 s f_{s}$ & $4 s f_{s}$ & $6 s f_{s}$ \\
\hline Healthy & $-58.11 \mathrm{~dB}$ & $-57.88 \mathrm{~dB}$ & $-57.78 \mathrm{~dB}$ & $-56.71 \mathrm{~dB}$ \\
Faulty & $-12.01 \mathrm{~dB}$ & $-23.63 \mathrm{~dB}$ & $-11.75 \mathrm{~dB}$ & $-23.24 \mathrm{~dB}$
\end{tabular}

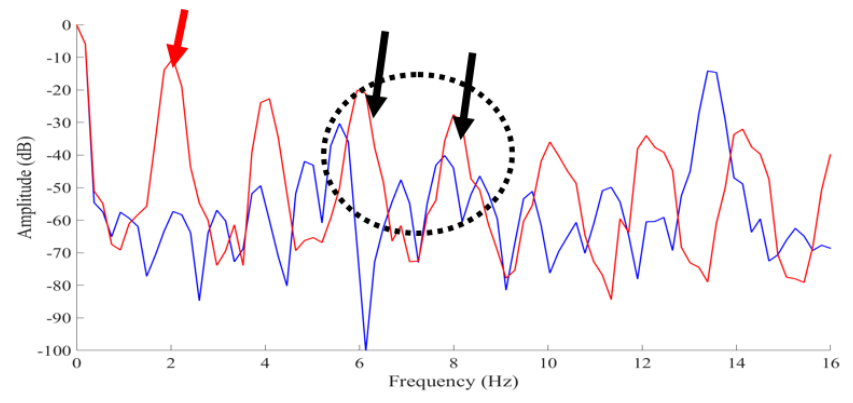

a)

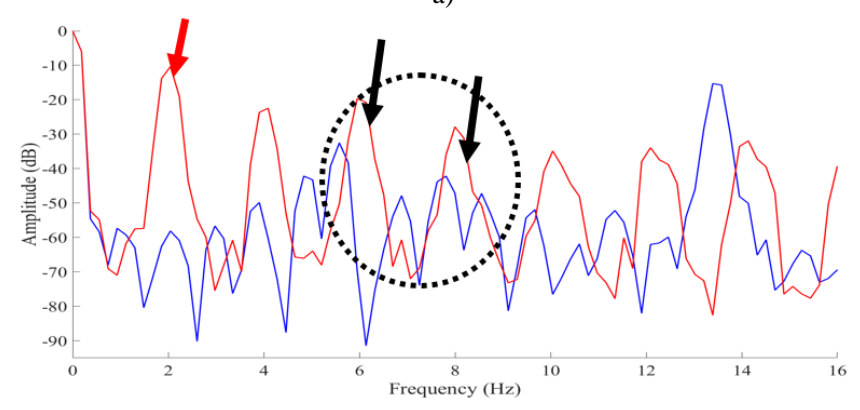

b)

Fig. 6. FFT spectra of the extracted $S\left(t, f_{o, 1}\right)$ information for healthy (blue) and faulty (red) motor at: a) $(7-6 s) f_{s}$ and b) $(7-8 s) f_{s}$.

Similar indications are provided by the spectra of the $7^{\text {th }}$ harmonic sidebands. The $6 s f_{s}$ and $8 s f_{s}$ components rise with amplitudes of $-21.12 d B$ and $-30.91 d B$ in the faulty motor regarding the signsture $7 f_{s}-6 s f_{s}$. The extracted spectra of the signature $7 f s-8 s f_{s}$ reveal amplitudes of the $6 s f_{s}$ and $8 s f_{s}$ components equal to $-20.74 d B$ and $-27.87 d B$ respectively, an increase of $12.53 \mathrm{~dB}$ and $19.35 \mathrm{~dB}$ respectively compared with the healthy motor.

TABLE III

FFT AMPLITUDES OF THE $7^{\mathrm{TH}}$ HARMONIC'S EXTRACTED COMPONENTS

\begin{tabular}{ccccc}
\hline \hline \multirow{2}{*}{ Case } & \multicolumn{2}{c}{$7{f f s-6 s f_{s}}^{2}$} & \multicolumn{2}{c}{$7 f s-8 s f_{s}$} \\
\cline { 2 - 5 } & $6 s f_{s}$ & $8 s f_{s}$ & $6 s f_{s}$ & $8 s f_{s}$ \\
\hline Healthy & $-30.32 \mathrm{~dB}$ & $-40.15 \mathrm{~dB}$ & $-32.53 \mathrm{~dB}$ & $-47.22 \mathrm{~dB}$ \\
Faulty & $-21.12 \mathrm{~dB}$ & $-30.91 \mathrm{~dB}$ & $-20.74 \mathrm{~dB}$ & $-27.87 \mathrm{~dB}$
\end{tabular}

\section{B. Experimental Results}

Regarding the experimental measurements, the trajectories' FFT spectra are presented in Fig. 7 for the $5^{\text {th }}$ harmonic and in Fig. 8 for the $7^{\text {th }}$ harmonic. The amplitudes of the components are shown in Table IV and Table $\mathrm{V}$ for the $5^{\text {th }}$ and the $7^{\text {th }}$ harmonic respectively for both motors. 


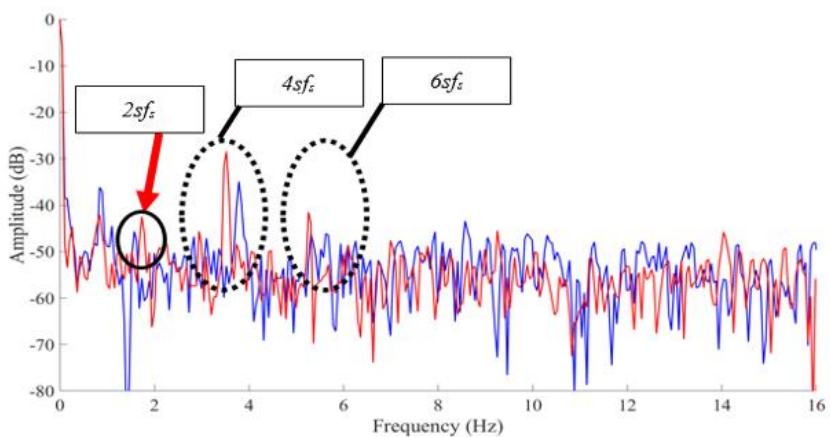

a)

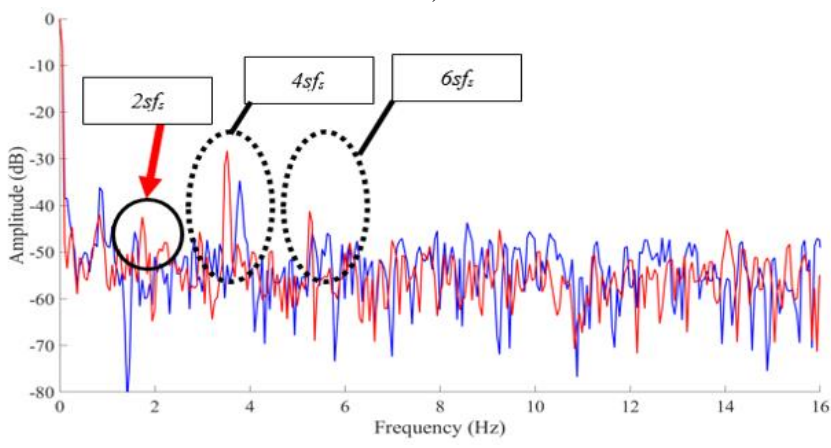

b)

Fig. 7. FFT spectra of the extracted $S\left(t, f_{o, 1}\right)$ information for the healthy (blue) and faulty (red) motor at: a) $(5-4 s) f_{s}$ and b) $(5-6 s) f_{s}$.

TABLE IV

FFT AMPLITUDES OF THE $5^{\text {TH }}$ HARMONIC'S EXTRACTED COMPONENTS

\begin{tabular}{ccccc}
\hline \hline \multirow{2}{*}{ Case } & \multicolumn{2}{c}{$5 f s-4 s f_{s}$} & \multicolumn{2}{c}{$5 f s-6 s f_{s}$} \\
\cline { 2 - 5 } & $4 s f_{s}$ & $6 s f_{s}$ & $4 s f_{s}$ & $6 s f_{s}$ \\
\hline Healthy & $-34.93 \mathrm{~dB}$ & $-46.18 \mathrm{~dB}$ & $-34.69 \mathrm{~dB}$ & $-45.91 \mathrm{~dB}$ \\
Faulty & $-28.49 \mathrm{~dB}$ & $-40.51 \mathrm{~dB}$ & $-28.27 \mathrm{~dB}$ & $-40.23 \mathrm{~dB}$
\end{tabular}

The amplitudes of the examined components at $4 s f_{s}$ and $6 s f_{s}$ frequencies (circled in dashed in Fig. 7) rise at the amplitudes of $-28.49 d B$ and $-40.51 d B$ respectively regarding the lower $5^{\text {th }}$ harmonic's sideband (Table IV). This implies an increase of $6.44 d B$ and $5.67 d B$ respectively, compared to the healthy motor. For the trajectory of the upper sideband, these spike at $-28.27 \mathrm{~dB}$ and $-40.23 \mathrm{~dB}$ respectively. Compared to the healthy motor, this is an increase of $6.42 d B$ and $5.68 d B$ respectively. Note that the component at $2 s f_{s}$ is dimly present in the low frequency rage for the healthy motor (red arrows in Fig. 7). This component is evident in the experiments, due to inherent cage asymmetries -like magnetic anisotropy or the cage porositywhich are not accounted for by 2D FEM. Hence, this component exists only in actual healthy motors, where these phenomena are implied by naturally existing manufacturing defects.

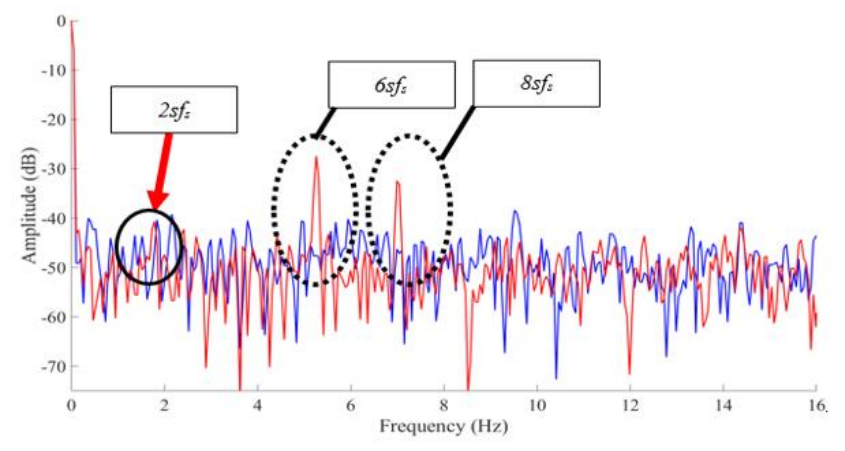

a)

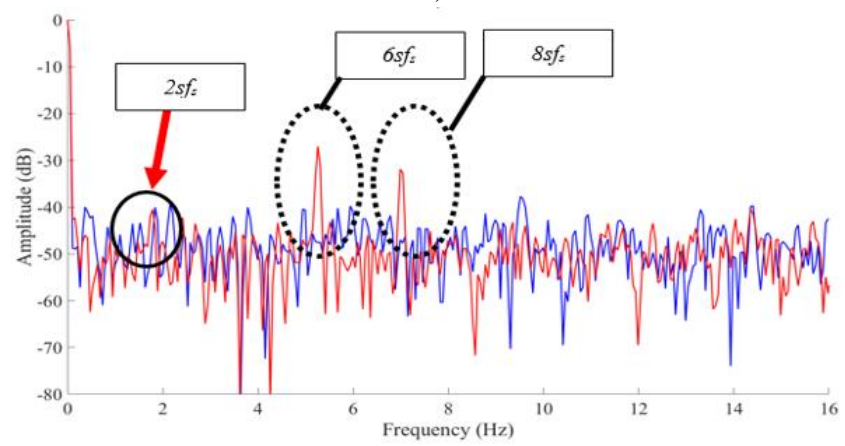

b)

Fig. 8. FFT spectra of the extracted $S\left(t, f_{o, 1}\right)$ information for the healthy (blue) and faulty (red) motor at: a) $(7-6 s) f_{s}$ and b) $(7-8 s) f_{s}$.

TABLE V

FFT AMPLITUDES OF THE $7^{\mathrm{TH}}$ HARMONIC'S EXTRACTED COMPONENTS

\begin{tabular}{ccccc}
\hline \multirow{2}{*}{ Case } & \multicolumn{2}{c}{$7 f s-6 s f_{s}$} & \multicolumn{2}{c}{$7 f_{s-8}-8 s f_{s}$} \\
\cline { 2 - 5 } & $6 s f_{s}$ & $8 s f_{s}$ & $6 s f_{s}$ & $8 s f_{s}$ \\
\hline Healthy & $-47.54 \mathrm{~dB}$ & $-47.16 \mathrm{~dB}$ & $-47.54 \mathrm{~dB}$ & $-47.65 \mathrm{~dB}$ \\
Faulty & $-27.42 \mathrm{~dB}$ & $-32.48 \mathrm{~dB}$ & $-27.03 \mathrm{~dB}$ & $-31.91 \mathrm{~dB}$
\end{tabular}

The amplitudes of the examined components at $6 s f_{s}$ and $8 s f_{s}$ frequencies (circled in dashed in Fig. 8) rise at the amplitudes of $-27.42 d B$ and $-32.48 d B$ respectively, regarding the lower $7^{\text {th }}$ harmonic's sideband (Table V). This implies an increase of $20.12 d B$ and $14.68 d B$ respectively, compared to the healthy motor. For the trajectory of the upper sideband, these spike at $-28.27 d B$ and $-40.23 d B$ respectively. Compared to the healthy motor, this is an increase of $6.42 d B$ and $5.68 d B$ respectively. Apart from the fact the $7^{\text {th }}$ harmonic's sidebands provide a compelling diagnostic value for rotor faults with the proposed approach; it is also interesting to report that the impact of the component at $2 s f_{s}$ is almost negligible for the $7^{\text {th }}$ harmonic's sidebands (red arrows in Fig. 8).

\section{CONCLUSION}

This work presented a new approach for the detection of rotor electrical faults in induction motors, ushering the presence of a subset of harmonic components in the low frequencies range. These components are revealed by frequency extraction of the fault-related trajectories' spectral information in measured phase current signals. Taking advantage of the speed-ripple effect, the spectral density information $S\left(t, f_{a, i}\right)$ is initially extracted via the Short-Time 
Fourier Transform for the a-th harmonic of interest. Thereafter, each trajectory is treated as a periodical time signal and is evaluated with the classical FFT, to track and detect the modulations implied by the fault. The proposed diagnostic method has been applied on both FEM simulations' and experimental data with success, while offering reliable online and non-intrusive diagnostic potential.

\section{ACKNOWLEDGMENTS}

The authors acknowledge the contribution of the company AE Advanced Electromagnetics BV, Netherlands for their assistance to build the test-bed as well as Mr. Jon Weston, TSI of Coventry University's EEC Faculty, for his assistance during the experimental measurements.

\section{REFERENCES}

[1] N. M. Elkasabgy, A. R. Eastham, G.E Dawson, "Detection of Broken Bars in the Cage Rotor on an Induction Machine", IEEE Transactions on Industry Applications, Vol. 28, No.1, pp 165-171, Jan/Feb 1992.

[2] F. Filippetti, G. Franceschini, C. Tassoni, P. Vas, "AI techniques in induction machines diagnosis including the speed ripple effect", IEEE Trans. on Ind. Appl., Vol. 34, No. 1, pp.98-108, Jan 1998.

[3] A. Bellini, F. Filippetti, G. Franceschini, C. Tassoni, G.B. Kliman, "Quantitative evaluation of induction motor broken bars by means of electrical signature analysis". IEEE Trans. on Ind. Appl., Vol. 37, No. 5, pp.1248-1255, Sep/Oct 2001

[4] A. Bellini, F. Filippetti, G. Franceschini, C. Tassoni, R. Passaglia, M. Saottini, G. Tontini, M. Giovannini, A. Rossi, "On-field experience with online diagnosis of large induction motors cage failures using MCSA", IEEE Trans. on Ind. Appl., Vol. 38, No. 4, pp.1045-1053, July/Aug 2002.

[5] W.T. Thomson \& R.J. Gilmore, "Motor Current Signature Analysis To Detect Faults In Induction Motor Drives-Fundamentals, Data Interpretation, And Industrial Case Histories". In Proc. of the 32nd Turbomachinery Symposium, 2003.

[6] W.T. Thomson \& M. Fenger, "Case histories of current signature analysis to detect faults in induction motor drives", IEEE IEMDC'03, Vol. 3, pp. 1459-1465, June 2003.

[7] A. Bellini, F. Filippetti, G. Franceschini, C. Tassoni, R. Passaglia, M. Saottini, M. Giovannini, "Mechanical failures detection by means of induction machine current analysis: a case history", $4^{\text {th }}$ IEEE SDEMPED ('03), pp. 322-326, Aug 2003.

[8] H. Henao, H. Razik, G.A. Capolino, "Analytical approach of the stator current frequency harmonics computation for detection of induction machine rotor faults", IEEE Trans. on Ind. Appl., Vol. 41, No. 3, pp.801-807, May/June 2005

[9] A. Bellini, C. Concari, G. Franceschini, E. Lorenzani, C. Tassoni, A. Toscani, "Thorough understanding and experimental validation of current sideband components in induction machines rotor monitoring", In IEEE Industrial Electronics, 32nd IEEE IECON ('06), pp. 49574962, Nov 2006.

[10] J.H. Jung, J.J. Lee, B.H. Kwon, "Online diagnosis of induction motors using MCSA", IEEE Trans. on Ind. Electronics, Vol. 53, No. 6, pp.1842-1852, Dec 2006.

[11] C. Bruzzese \& E. Santini, "On the frequency dependence of harmonic current side-band (HCSB) based rotor fault indicators for three-phase cage machines", IEEE SDEMPED '07, pp. 231-235, Sep 2007.

[12] M.E.H. Benbouzid \& G.B. Kliman, "What stator current processingbased technique to use for induction motor rotor faults diagnosis?", IEEE Trans. on Energy Conv., Vol. 18, No. 2, pp.238-244, June 2003.

[13] F. Cupertino, E. De Vanna, L. Salvatore, S. Stasi, "Comparison of spectral estimation techniques applied to induction motor broken bars detection”, $4^{\text {th }}$ IEEE SDEMPED ('03), pp. 129-134, Aug. 2003.
[14] G. Didier, E. Ternisien, O. Caspary, H. Razik, "A new approach to detect broken rotor bars in induction machines by current spectrum analysis", Elsevier MSSP, Vol. 21, No. 2, pp.1127-1142, Feb 2007.

[15] I. Jaksch, P. Fuchs, "Rotor cage faults detection in induction motors by motor current demodulation analysis", IEEE SDEMPED '07, pp. 247 252, Sep 2007.

[16] A. Bellini, A. Yazidi, F. Filippetti, C. Rossi, G.A. Capolino, "High frequency resolution techniques for rotor fault detection of induction machines", IEEE Trans. on Ind. Electronics, Vol. 55, No. 12, pp.42004209, Dec 2008.

[17] A. Stefani, A. Bellini, F. Filippetti, "Diagnosis of induction machines' rotor faults in time-varying conditions", IEEE Trans. on Ind. Electronics, Vol. 56, No. 11, pp.4548-4556, Nov 2009.

[18] R. Puche-Panadero, M. Pineda-Sanchez, M. Riera-Guasp, J. RogerFolch, J.A. Antonino-Daviu, J. Perez-Cruz, "Diagnosis of rotor bar breakages based on the Hilbert transform of the current during the startup transient", IEEE IEMDC'09, pp. 1434-1440, May 2009.

[19] G.A. Jimenez, A.O. Munoz, M.A. Duarte-Mermoud, "Fault detection in induction motors using Hilbert and Wavelet transforms", Electrical Engineering, Vol. 89, No. 3, pp.205-220, Jan 2007.

[20] A. Sapena-Bano, M. Pineda-Sanchez, R. Puche-Panadero, J. MartinezRoman, Ž. Kanović, "Low-cost diagnosis of rotor asymmetries in induction machines working at a very low slip using the reduced envelope of the stator current", IEEE Trans. on Energy Conv., Vol. 30, No. 4, pp. 1409-1419, Dec 2015.

[21] M. Riera-Guasp, J.A. Antonino-Daviu, M. Pineda-Sanchez, R. PuchePanadero, J. Pérez-Cruz, "A general approach for the transient detection of slip-dependent fault components based on the discrete wavelet transform", IEEE Trans. on Ind. Electronics, Vol. 55, No. 12, pp.4167-4180, Dec 2008.

[22] J.A. Antonino-Daviu, S.B. Lee, E. Wiedenbrug, "Reliable detection of rotor bar failures in induction motors operating in petrochemical plants", Petroleum and Chemical Industry Conference Europe, 2014, pp. 1-9, IEEE, June 2014.

[23] Y. Gritli, S.B. Lee, F. Filippetti, L. Zarri, “Advanced diagnosis of outer cage damage in double-squirrel-cage induction motors under timevarying conditions based on wavelet analysis", IEEE Trans. on Ind. Appl., Vol. 50, No. 3, pp.1791-1800, May 2014.

[24] M. Riera-Guasp, M. Pineda-Sanchez, J. Pérez-Cruz, R. PuchePanadero, J. Roger-Folch, J.A. Antonino-Daviu, "Diagnosis of induction motor faults via Gabor analysis of the current in transient regime", IEEE Trans. on Instr. \& Measurement, Vol. 61, No. 6, pp.1583-1596, June 2012.

[25] E. Cabal-Yepez, A.G. Garcia-Ramirez, R.J. Romero-Troncoso, A. Garcia-Perez, R.A. Osornio-Rios, "Reconfigurable monitoring system for time-frequency analysis on industrial equipment through STFT and DWT", IEEE Trans. on Ind. Informatics, Vol. 9, No. 2, pp.760-771, May 2013.

[26] M. Lopez-Ramirez, R.J. Romero-Troncoso, D. Morinigo-Sotelo, O. Duque-Perez, L.M. Ledesma-Carrillo, D. Camarena-Martinez, GarciaA. Perez, "Detection and diagnosis of lubrication and faults in bearing on induction motors through STFT", IEEE CONIELECOMP'16, pp. 13-18, Feb 2016

[27] J.A. Antonino-Daviu, P. Popaleny, "Detection of Induction Motor Coupling Unbalanced and Misalignment via Advanced Transient Current Signature Analysis. XIII IEEE ICEM ('18), pp. 2359-2364, Sep 2018.

[28] J. Pons-Llinares, J. Antonino-Daviu, J. Roger-Folch, D. MoríñigoSotelo, O. Duque-Pérez, "Mixed eccentricity diagnosis in Inverter-Fed Induction Motors via the Adaptive Slope Transform of transient stator currents", Elsevier MSSP, Vol. 48 (1-2), pp.423-435, Oct 2014.

[29] M. Blodt, J. Regnier, J. Faucher, "Distinguishing load torque oscillations and eccentricity faults in induction motors using stator current Wigner distributions", IEEE Trans. on Ind. Appl., Vol. 45, No. 6, pp.1991-2000, Nov/Dec 2009.

[30] V. Climente-Alarcon, J.A. Antonino-Daviu, M. Riera-Guasp, M. Vlcek, "Induction motor diagnosis by advanced notch FIR filters and the Wigner-Ville distribution”, IEEE Trans. on Ind. Electronics, Vol. 61, No. 8, pp.4217-4227, Aug 2014.

[31] C. Concari, G. Franceschini, C. Tassoni, A. Bellini, "Torque and field currents peculiarities under different induction machine troubles", IEEE SDEMPED'07, pp. 302-308, Sep 2007. 
[32] K.N. Gyftakis, D.V. Spyropoulos, J.C. Kappatou, E.D. Mitronikas, “A novel approach for broken bar fault diagnosis in induction motors through torque monitoring", IEEE Trans. on Energy Conversion, Vol. 28, No. 2, pp.267-277, June 2013.

[33] A. Bellini, C. Concari, G. Franceschini, C. Tassoni, A. Toscani, "Vibrations, currents and stray flux signals to asses induction motors rotor conditions", 32nd IEEE IECON ('06), pp. 4963-4968, Nov. 2006.

[34] C. Concari, G. Franceschini, C. Tassoni, "Differential diagnosis based on multivariable monitoring to assess induction machine rotor conditions", IEEE Trans. on Ind. Electronics, Vol. 55, No. 12, pp.4156-4166, Dec 2008.

[35] P.A. Panagiotou, I. Arvanitakis, N. Lophitis, J.A. Antonino-Daviu, K.N. Gyftakis, "Analysis of Stray Flux Spectral Components in Induction Machines under Rotor Bar Breakages at Various Locations", XIII IEEE ICEM ('18), pp. 2345-2351, Sep 2018.

[36] J.A. Antonino-Daviu, K.N. Gyftakis, R. Garcia-Hernandez, H. Razik, A.J.M. Cardoso, "Comparative influence of adjacent and non-adjacent broken rotor bars on the induction motor diagnosis through MCSA and ZSC methods”, 41st IEEE IECON ('15), pp. 1680-1685, Nov 2015.

[37] A.G. Garcia-Ramirez, L.A. Morales-Hernandez, R.A. Osornio-Rios, A. Garcia-Perez, R.J. Romero-Troncoso, "Thermographic technique as a complement for MCSA in induction motor fault detection", IEEE ICEM'14, pp. 1940-1945, Sep 2014.

[38] P. Popaleny, J.A. Antonino-Daviu, "Electric Motors Condition Monitoring Using Currents and Vibrations Analyses", XIII IEEE ICEM ('18) , pp. 1834-1840, Sep 2018.

[39] A. Bellini, G. Franceschini, C. Tassoni, "Monitoring of induction machines by maximum covariance method for frequency tracking", IEEE Trans. on Ind. Appl., Vol. 42, No. 1, pp.69-78, Jan 2006.

[40] V. Choqueuse \& M. Benbouzid, "Induction machine faults detection using stator current parametric spectral estimation", Elsevier MSSP, 52, pp.447-464, Feb 2015.

[41] P. Gangsar \& R. Tiwari, "Comparative investigation of vibration and current monitoring for prediction of mechanical and electrical faults in induction motor based on multiclass-support vector machine algorithms", Elsevier MSSP, 94, pp.464-481, Sep 2017.

[42] G. Georgoulas, V. Climente-Alarcon, J.A. Antonino-Daviu, C.D. Stylios, A. Arkkio, G. Nikolakopoulos, "A multi-label classification approach for the detection of broken bars and mixed eccentricity faults using the start-up transient", 14th IEEE Intern. Conf. on Industrial Informatics (INDIN'16), pp. 430-433, July 2016.

[43] E. Cabal-Yepez, M. Valtierra-Rodriguez, R.J. Romero-Troncoso, A. Garcia-Perez, R.A. Osornio-Rios, H. Miranda-Vidales, R. AlvarezSalas, "FPGA-based entropy neural processor for online detection of multiple combined faults on induction motors", Elsevier MSSP, Vol. 30, pp.123-130, July 2012.

[44] J.A. Antonino-Daviu, A. Quijano-Lopez, V. Fuster-Roig, C. Nevot, "Case stories of induction motors fault diagnosis based on current analysis". In Petroleum and Chemical Industry Conference Europe (PCIC Europe), pp. 1-9, June 2016.

[45] M.W. Trethewey, "Window and overlap processing effects on power estimates from spectra", Elsevier, Mechanical Systems and Signal Processing, Vol. 14, No. 2, pp.267-278, March 2000.

[46] P. A. Panagiotou, I. Arvanitakis, N. Lophitis, J.A. Antonino-Daviu, K. N. Gyftakis, "On the broken bar diagnosis using time-frequency analysis: Is one spectral representation enough for the characterization of monitored signals?", IET Electric Power Applications, in Press, Feb/Mar 2019.

[47] C. Wang, R.X. Gao, R. Yan, "Unified time-scale-frequency analysis for machine defect signature extraction: theoretical framework", Elsevier MSSP, Vol. 23, No. 1, pp.226-235, Jan 2009.

[48] C. Li, X. Wang, Z. Tao, Q. Wang, S. Du, "Extraction of time varying information from noisy signals: An approach based on the empirical mode decomposition", Elsevier MSSP, Vol. 25, No. 3, pp.812-820, Apr 2011.

[49] X. Zhu, Z. Zhang, J. Gao, W. Li, "Two robust approaches to multicomponent signal reconstruction from STFT ridges", Elsevier MSSP, 115, pp.720-735, Jan 2019

\section{AUTHORS' INFORMATION}

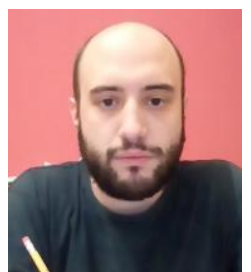

Panagiotis A. Panagiotou was born in Thessaloniki, Greece, in 1989. He received the 5 year Diploma in Electrical \& Computer Engineering from the University of Patras, Greece, in 2015 and the MSc in Complex Systems \& Network Theory from Aristotle University of Thessaloniki, Department of Mathematics in 2016. Currently, he is a Ph.D Candidate at Coventry University, UK.

His research is focused on condition monitoring and fault diagnosis of electric motors for industrial and EV applications, as well as statistical modelling and signal processing for diagnostic purposes.

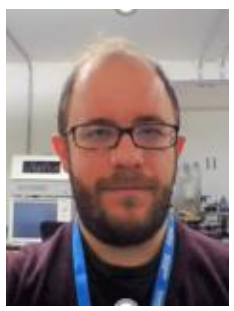

Ioannis Arvanitakis received his 5 year Diploma in Electrical \& Computer Engineering from the University of Patras, Greee, in 2009 and the PhD from the same institution in 2017, entitled "Navigation and Collaborative Mapping of a Team of Moile Robots". He is currently an Assistant Lecturer in Electrical and Electronics, School of Computing, Electronics \&Mathematics, Coventry University, UK

His main research interrests include: Navigation, Guidance and Control, Obstacle Avoidance algorithms, Unmand Ground Vehicles, Simultaneous Localization And Mapping (SLAM) algorithms, Nonlinear Modelling, Optimization Theory.

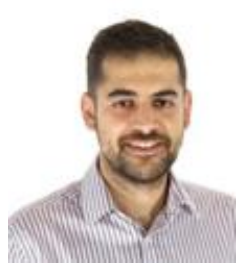

Neophytos Lophitis is currently a Senior Lecturer of Electrical Engineering at the School of Computing, Electronics \& Mathematics and an associate with the Faculty Research Institute Future Transport \& Cities within the Faculty of Engineering, Environment \& Computing, Coventry University, UK. He is also an Academic Collaborator with the High Voltage Microelectronics Laboratory within the Department of Engineering, Electrical Division, of the University of Cambridge, UK. He received the B.A. and M.Eng degrees in 2009 and the $\mathrm{PhD}$ degree in 2014, all from the University of Cambridge.

His research activities are ini optimization, design, degradation and reliability of high voltage microelectronic devices and electrical energy storage and conversion systems.

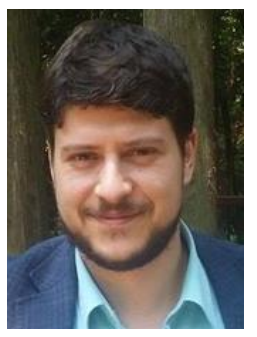

Konstantinos N. Gyftakis (M'11) was born in Patras, Greece, in May 1984. He received the Diploma in Electrical and Computer Engineering from the University of Patras, Patras, Greece in 2010. He pursued a Ph.D in the same institution in the area of electrical machines condition monitoring and fault diagnosis (2010-2014). Then he worked as a Post-Doctoral Research Assistant in the Dept. of Engineering Science, University of Oxford, UK (2014-2015). Then he worked as Lecturer (2015 2018) and Senior Lecturer (2018-2019) in the School of Computing, Electronics and Mathematics and as an Associate with the Research Institute for Future Transport and Cities, Coventry University, UK. Additionally, since 2016 he has been a member of the "Centro de Investigação em Sistemas Electromecatrónicos” (CISE), Portugal. Since 2019 he has been a Lecturer in Electrical Machines, University of Edinburgh UK

His research interests focus in the area of fault diagnosis, condition monitoring and degradation of electrical machines. He has authored/coauthored more than 70 papers in international scientific journals and conferences and a chapter for the book: "Diagnosis and Fault Tolerance of Electrical Machines, Power Electronics and Drives”, IET, 2018 